\title{
Locking compression plate for proximal humerus fracture: A functional outcome analysis.
}

\author{
Khairnar A. ${ }^{1}$, Patil L. ${ }^{2}$ \\ ${ }^{1}$ Dr. Amol Khairnar, Assistant Professor, Department of Orthopedics, S.B.H. GMC Dhule, Maharashtra, India, ${ }^{2}$ Dr. Lalit \\ Patil, Ex. Assistant Professor, Department of Orthopedics, S.B.H. GMC Dhule, Maharashtra, India. \\ Corresponding Author: Dr. Amol Khairnar, Assistant Professor, Department of Orthopedics, S.B.H. GMC Dhule, \\ Maharashtra, India. Email: amolkortho@gmail.com
}

\begin{abstract}
Introduction: Proximal humerus fractures are often the result of a fall in an osteoporotic patient, but can also occur in young adults due to high energy trauma. They account for $4-5 \%$ of all fractures. Over the past few decades, several operative techniques have been described for the treatment of proximal humerus fractures. Currently locking compression plate is gaining popularity. This plate combines the feature of compression of regular plate and locking into one system. Methods: The present study is a prospective study conducted at Department of Orthopedics, S.B.H. GMC Dhule over a period of 2 years from March 2015 to March 2017. Total 34 patients of proximal humerus fracture which were admitted in Orthopedics ward were included in the present study. X ray of proximal humerus was taken and the fractures were classified according to Neer's classification. All the patients were subjected for open reduction and internal fixation withlocking compression plate i.e. PHILOS (Proximal Humerus Interlocking System). Fracture approached through anterior deltopectoral approach. Post operatively patients were mobilized as early as possible. Patients were followed up and functional outcome was assessed using Neer's functional scoring system. Mean follow up was 1 year. Results: All the 34 patients of displaced proximal humerus were operated by open reduction and internal fixation using locking compression plate (PHILOS). Among these 19 (55.88\%) were males and 15 (44.12\%) were females. Age of patients ranged from 29 to 75 years with mean of 52 years. All fractures were classified according to Neer's functional scoring system. 8 (23.5\%) patientswere typeII, 11(32.35\%) were type III and 15 (44.11\%) were type IV. Functional outcome was assessed using Neer's functional scoring system. According to Neer's score $60 \%$ of our patients had satisfactory to excellent results and $40 \%$ of the patients had unsatisfactory to poor results. Conclusion: According to present study results of locking compression plate, PHILOS, for proximal humerus fracture type II and type III are satisfactory and encouraging in all age groups. Still there is scope to improve results in type IV fractures especially in elderly with osteoporotic bones.
\end{abstract}

Key words: Proximal humerus fractures, Locking compression plate, Open reduction internal fixation

\section{Introduction}

Proximal humerus fractures are often the result ofa fall in an osteoporotic patient, but can also occur in young adults due to high energy trauma. They account for 4$5 \%$ of all fractures [1,2]. Fractures of proximal humerus are still an unsolved problem in many ways. Disagreement exists regarding reliability of classification system.

The indication for surgical management continues to be modified. Fixation techniques are myriad and none is ideal for all cases. About $80 \%$ of fractures of the

Manuscript Received: $14^{\text {th }}$ August 2018

Reviewed: $24^{\text {th }}$ August 2018

Author Corrected: $30^{\text {th }}$ August 2018

Accepted for Publication: $4^{\text {th }}$ September 2018 proximal part of the humerusare undisplaced or minimally displaced and yield a good functional result when treated non operatively, but another $20 \%$ of fracture are a therapeutic challenge and have variable prognosis dueto various complications like failure of osteosynthesis, avascular necrosis of the humeral head, and also a nonunion or malunion of the fracture, which may all result in a painful shoulder with poor function $[3,4,5]$.

For optimal treatment of displaced or unstable fractures various techniques, including open reduction and internal fixation with proximal humeral plates, intramedullary nailing, percutaneous or minimally invasive 


\section{Original Research Article}

techniques with pins or screws and arthroplasty, have been described in literature [6,7-10]. Currently locking compression plate is gaining popularity. This plate combines the feature of compression of regular plate with locking into one system. It provides angular stability and act as an internal fixator [11]. The present study was carried out to assess the functional outcome of the displaced proximal humerus fractures treated with locking compression plate.

\section{Materials and Methods}

The present study is a prospective study conducted in department of Orthopedics, S.B.H.GMC Dhule over a period of 2 years from March 2015 to March 2017.

Inclusion criteria- Displaced two part, three part and four part fractures of proximal humerus with or without shoulder dislocation in age group $>18$ years and surgically fit patients were included.

Exclusion criteria- Acute infections, pathological fractures, associated neuro vascular injury, fractures in children during growth phase and compound fractures were excluded.

Statistical analysis- The statistical analysis was carried out with SPSS VER. 18.0 Software. All the data were presented as mean, standard deviation, and percentage of efficacies. Chi-square and paired ' $t$ ' test is used to evaluate the statistical significance in Neer's study $(\mathrm{P}<0.05)$ is considered as significant.

Total 34 patients of proximal humerus fracture which were admitted in orthopedics ward were included in the present study. X ray of proximal humerus was taken and the fractures were classified according to Neer's classification.
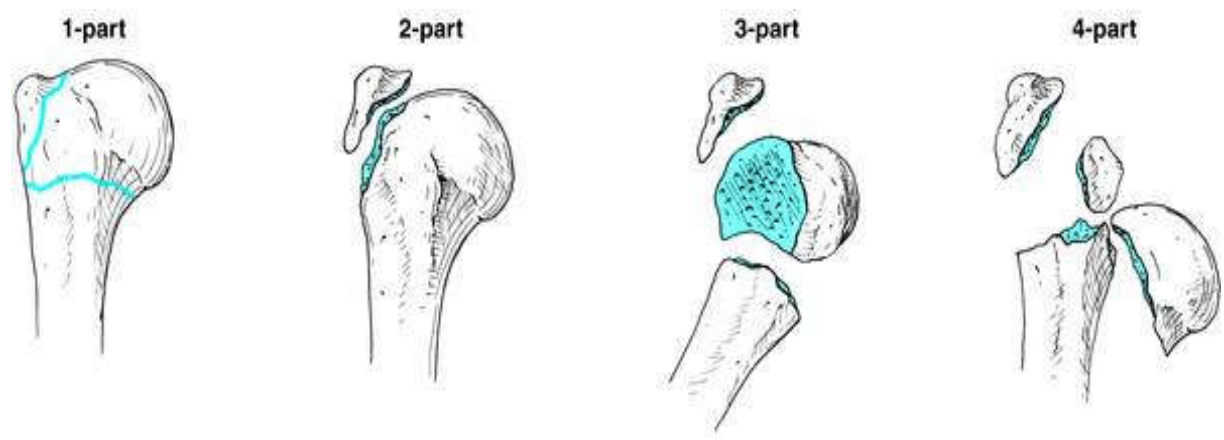

\section{Neer's Classification}

Patients were evaluated for surgical fitness. All the patients were subjected for open reduction and internal fixation with locking compression plate i.e. PHILOS (Proximal Humerus Interlocking System).

Surgical approach- A deltopectoral approach was used. Once through the interval, an extensive hematoma is usually encountered and is evacuated by aspiration or digitally toexpose the fracture. Slight abduction of the arm relaxes the deltoid muscle and enables better access to the humeral head. The long head of the biceps tendon is identified at the upper border of the pectoralis major muscle, and its course is followed proximally. This tendon is important in orienting the anatomy of the proximal humerus because it runs in the inter tubercular groove between the greater and lesser tuberosities. The biceps tendon is particularly useful for orientation in the presence of four part fractures, when anatomy can be significantly distorted. Prior to attempted fracture reduction, the rotator cuff is generously tagged with non absorbable sutures anteriorly, posteriorly, and superiorly to assist with reduction of the fracture fragments and ultimately, to reinforce fixation of the fracture to the plate.

Now the head fragment can be gently manipulated under direct visualization with aperiosteal elevator introduced into the fracture gaps. Inthe presence of varus tilt of the head fragment, the position can be corrected by pulling on the superior suture loop through the supraspinatus tendon while maintaining longitudinal traction on the arm. Tagged tuberosity fragments can be reduced to the humeral shaftand may also indirectly reduce a head fragment. Once the head fragment has been reduced, the tuberosities arepulled together with the sutures and fitted via digital manipulation. Poor results 


\section{Original Research Article}

have been shown with improper reduction of the tuberosities. In comminuted fractures, temporary fixation with K-wires is recommended to hold the fracture reduction. Care must be taken so that the wires do not interfere with subsequent plate positioning. After temporary fracture reduction is achieved, the precontoured anatomic locking compression plate, PHILOS, is positioned approximately $1 \mathrm{~cm}$ distal to the upper edge of the greater tuberosity to avoid subacromial impingement. However, care should also be taken to avoid placing the plate too low which could prevent optimal screw placement in the humeral head. Correct plate position checked and the adequacy offracture reduction confirmed on fluoroscopic imaging. Kwires are temporarily inserted into the screw holes tohold the plate in place. With the plate appropriately positioned and the fracture fragments reduced, proximal and distal screws are placed in the plate. We prefer to insert the tip of each locking screw to adistance at least $5 \mathrm{~mm}$ short of the subchondral bone. Placement of calcar screws is of paramount importance to avoid varus collapse of the fracture. When all screws have been placed, the rotator cuff sutures are threaded through the small holes in the proximal end of the plate and tied down for additional fixation. During wound closure, we placed a drain deep to the deltopectoral interval to close down any dead space. All patients received perioperative antibiotics. Adjuvant bone grafting or bone graft substitutes were not used.

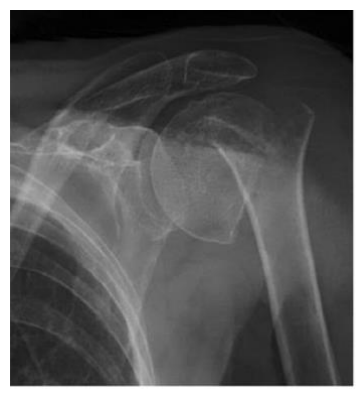

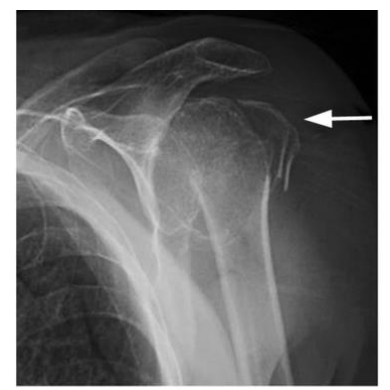

Pre-op

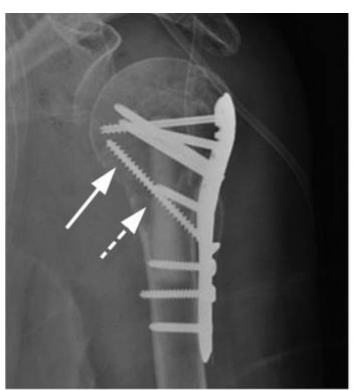

Post-op

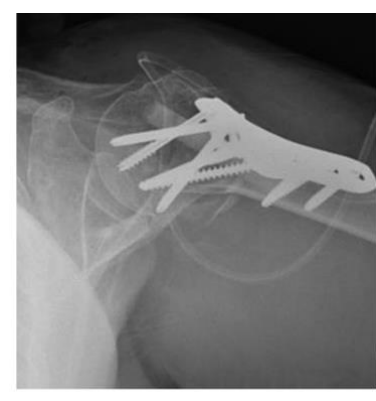

Postoperative care- Postoperatively, the arm was immobilized in a should erimmobilizer. The drain removed 48 hours after surgery. Postoperatively patients were mobilized as early as possible depending upon stability of fixation. The patient progresses through a three-phase rehabilitation program consisting of I) Passive or assisted exercises. II) Active exercises starting at approximately 4-6 weeks postoperatively. III) Strengthening or resisted exercises beginning 10 to12 weeks after surgery.

Follow up- All the patients were followed up by clinical and radiographic assessment immediately after treatment andat 1,3, and 6 months and 1 year. Radiographic assessment was made by anteroposterior and axillary views taken immediately after surgery. Union was defined with presence of bridge callus in two views and AVN was defined with loss of bony substance and presence of diffuse sclerotic area inthe humeral head. Malunion was defined if there was displacement of more than $5 \mathrm{~mm}$ or an angulation of morethan 40 degree of any fragment. The functional assessment was done according to Neer's functional scoring system at the end of 1 year.

\section{Results}

Table-1: Age wise distribution of patients

\begin{tabular}{|c|c|c|}
\hline Age in years & No of patients & Percentage \\
\hline $20-40$ & 6 & $17.6 \%$ \\
\hline $40-60$ & 10 & $29.4 \%$ \\
\hline$>60$ & 18 & $52.94 \%$ \\
\hline
\end{tabular}

Table-2: Sex distribution of patients

\begin{tabular}{|c|c|c|}
\hline Sex & No. Of Patients & Percentage \\
\hline Males & 19 & $55.88 \%$ \\
\hline Females & 15 & $44.12 \%$ \\
\hline
\end{tabular}


Original Research Article

Table-3: Neer's classification wise distribution of fracture

\begin{tabular}{|c|c|c|}
\hline Neer's Fracture Type & No. Of Patients & Percentage \\
\hline Type II & 8 & $23.5 \%$ \\
\hline Type III & 11 & $33.35 \%$ \\
\hline Type IV & 15 & $44.11 \%$ \\
\hline
\end{tabular}

Table-4: Average Neer's functional score according to fracture type

\begin{tabular}{|c|c|}
\hline Neer's fracture Type & Average Score \\
\hline Type II & 80 \\
\hline Type III & 70 \\
\hline Type IV & 50 \\
\hline
\end{tabular}

All the 34 patients of displaced proximal humerus were operated by open reduction and internal fixation using locking compression plate i.e. PHILOS (Proximal Humerus Inter locking System). Among these 19 (55.88\%) were males and $15(44.12 \%)$ were females. Age of patients ranged from 29 to 75 years with mean of 52 years. All fractures were classified according to Neer's classification system. 8 (23.5\%) patients were type II,11 (33.35\%) were type III and 15(44.11\%) were type IV.

Functional outcome was assessed using Neer's functional scoring system. Average Neer's score for type II fracture was 80, for type III fracture 70 and for type IV was 50. According to Neer's score $60 \%$ of our patients had satisfactory to excellent results and $40 \%$ of the patients had unsatisfactory to poor results. High percentage of unsatisfactory to poor results was observed in Neer's type IV fractures especially in patients with age $>60$ years and with highly osteoporotic bones.

All the fractures united without any infection although there were some complications like AVN with humeral head collapse in 1 patient with type IV fracture and implant loosening accouted in one. Varus malunion was observed in 5 patients.

\section{Discussion}

Proximal humeral fractures represent an increasing challenge for health-care system because of the increasing proportion of elderly individuals in the population. The majority of patients with these fractures are more than 60 years old, and most these fractures are related to osteoporosis.

Nevertheless, stable reduction is essential for healing of these fractures and for achieving early functional recovery of the shoulder. In patients with osteoporotic bones and/or comminuted fractures, operative stabilization is challenging and remains controversial.

Newer techniques involving the use of locking compression plates and screws with angular stability have been introduced in order to avoid complications associated with traditional plates. The anatomic locking compression plates (PHILOS: proximal humerus interlocking system) are designed to maintain a stable fracture reduction even in osteoporotic bone. Advantages of these plates include gentle fracture reduction with the use of indirect reduction maneuvers, resistance to screwpull out even in patients with poor bone stock because of the combination of fixed-angle screw - plate locking and three - dimensional placement of screws in humeral head and possibility of early exercise and a short period of immobilization because of high initial stability achieved [12].

Brunner et al. evaluated the incidence of complications and functional outcome after open reduction and internal fixation with PHILOS. Study was prospective, multicenter study between September 2002 to September 2005, with 158 fractures in 157 patients.

They had primary screw perforation of $14 \%$ and secondary screw perforation of $8 \%$ and a vascular necrosis of humeral head $8 \%$.

They concluded that fixation with PHILOS plate preserves achieved reduction and a good functional outcome can be expected. More accurate screw length 


\section{Original Research Article}

measurement and shorter screw selection should prevent primary screw perforation [13]. Liu et al in 2010 concluded that treatment of proximalhumeral fractures in elderly patients with application of PHILOS plate combined with injectable artificial bone as satisfactory, especially suitable for osteoporotic and comminuted proximal humeral fractures. They studied 17 patients from March 2007 to March 2009 with an average age 71 years (66 to 81$)$. The clinical outcome was excellent in 9 patients, good in 6 , moderate in 2 cases [14].

Though in our study we did not use any bone grafts or bone graft substitutes, results are comparable.

Various fixation methods have been used in the past for treatment of proximal humeral fractures which showed variable outcomes. Complications like screw loosening, subacromial impingement and a vascular necrosis of humeral head upto $40 \%$ has been reported with AO-T plates and clover leaf plates [15,16]. According to Weinsten $\mathrm{D}$ et al and Walsh $\mathrm{S}$ et al locking plates provide better stability than conventional plates that were used in the past $[17,18]$.

In the present study proximal humerus fractures were observed commonly in elderly age group (mean 52 years) which is comparable with the findings by Robinson C et al [19].

In a study carried out by Arumugam $\mathrm{S}$ et al satisfactory to excellent results were found in $76.7 \%$ of patients while poor results were found in $23.3 \%$ of the patients [20]. These findings slightly vary from the findings of present study where satisfactory to excellent results were found in $60 \%$ of patients while poor results were found in $40 \%$ of the patients. The slight variation is attributable to more no. of type IV patients in the present study.

\section{Conclusion}

According to present study results of locking compression plate for proximal humerus fracture type II and type III are satisfactory and encouraging in all age groups. Still there is scope to improve results in type IV fractures especially in elderly with osteoporotic bones.

Conflict of interest: None declared.

Funding: Nil, Permission from IRB: Yes

\section{References}

1. Helmy N, Hintermann B. New trends in the treatment of proximal humerus fractures. Clin Orthop Relat Res. 2006 Jan; 442:100-8.
2. Kristiansen B, Barfod G, Bredesen J, et al. Epidemiology of proximal humeral fractures. Acta Orthop Scand. 1987 Feb;58(1):75-7.

3. Iannotti J P, Ramsey M L, Williams G R, Warner J P. Non prosthetic management of proximal humeral fractures. J Bone Joint Surg (Am) 2003; 85: 1578-93.

4. Paavolainen P, Björkenheim JM, Slätis P, Paukku P. Operative treatment of severe proximal humeral fractures. Acta Orthop Scand. 1983 Jun; 54(3):374-9.

5. Wijgman AJ, Roolker W, Patt TW, et al. Open reduction and internal fixation of three and four-part fractures of the proximal part of the humerus. J Bone Joint Surg Am. 2002 Nov;84-A(11):1919-25.

6. Resch H, Povacz P, Fröhlich R, Wambacher M. Percutaneous fixation of three- and four-part fractures of the proximal humerus. J Bone Joint Surg Br. 1997 Mar; 79(2):295-300.

7. Mittlmeier TW, Stedtfeld HW, Ewert A, et al. Stabilization of proximal humeral fractures with an angular and sliding stable antegrade locking nail (Targon PH). J Bone Joint Surg Am. 2003;85-A Suppl 4: $136-46$.

8. Fankhauser F, Boldin C, Schippinger G, et al. A new locking plate for unstable fractures of the proximal humerus. Clin OrthopRelat Res. 2005 Jan; (430): 176-81.

9. Wanner GA, Wanner-Schmid E, Romero J, et al. Internal fixation of displaced proximal humeral fractures with two one-third tubular plates. J Trauma. 2003 Mar; 54(3):536-44. doi:10.1097/01.TA. 000005 2365. 96538.42

10. Schmal H, Klemt C, Südkamp NP. [Evaluation of shoulder arthroplasty in treatment of four-fragment fractures of the proximalhumerus]. Unfallchirurg. 2004 Jul; 107(7):575-82.doi:10.1007/s00113-004-0772-4

11. Moonot P, Ashwood N, Hamlet M. Early results for treatment of three- and four-part fractures of the proximal humerus using the PHILOS plate system. J Bone Joint Surg Br. 2007 Sep;89(9):1206-9.doi:10. 1302/0301-620X.89B9.18528

12. Palvanen M, Kannus P, Niemi S, Parkkari J. Update in the epidemiology of proximal humeral fractures. Clin Orthop Relat Res. 2006 Jan;442:87-92. 


\section{Original Research Article}

13. Brunner F, Sommer C, Bahrs C, et al. Open reduction and internal fixation of proximal humerus fractures using a proximal humerallocked plate: a prospective multicenter analysis. J Orthop Trauma. 2009 Mar; 23 (3):163-72. doi: 10.1097/BOT. 0b013e $3181920 \mathrm{e} 5 \mathrm{~b}$.

14. Liu XW, Fu QG, Xu SG, Zhang CC, Su JC, Wang $\mathrm{PF}$, et al. Application of PHILOS plate with injectable artificial bone for the treatment ofproximal humeral fractures in elderly patients.ZhongguoGushang. 2010; 23 (3):180-2.

15. Rees J, Hicks J, Ribbans W. Assessment and management of three- and four-part proximal humeral fractures. Clin Orthop Relat Res. 1998 Aug; (353): 18-29.

16. Kristiansen B, Christensen SW. Plate fixation of proximal humeral fractures. Acta Orthop Scand. 1986 Aug; 57(4):320-3.
17. Weinstein DM, Bratton DR, Ciccone WJ 2nd, Elias JJ. Locking plates improve torsional resistance in the stabilization of three-part proximal humeral fractures. J Shoulder Elbow Surg. 2006 Mar-Apr;15(2):239-43.doi: 10. 1016/j.jse.2005.08.006

18. Walsh S, Reindl R, Harvey E, et al. Biomechanical comparison of a unique locking plate versus a standard plate for internal fixation of proximal humerus fractures in a cadaveric model. Clin Biomech (Bristol, Avon). 2006 Dec; 21(10):1027-31. Epub 2006 Aug 17.doi:10. 1016/j.clinbiomech.2006.06.005

19.Zyto K. Non-operative treatment of comminuted fractures of the proximal humerus in elderly patients. Injury. 1998 Jun; 29(5):349-52.

20. Arumugam S, Arumugam V, Raviraman V. Surgical management of proximal humerus fracture treated with locking compression plate. Int J Res Orthop 2017; 3: 1165-9.

\section{How to cite this article?}

Khairnar A, Patil L. Locking compression plate for proximal humerus fracture: A functional outcome analysis. Surgical Update: Int J surg Orthopedics.2018;4(3):115-120.doi:10.17511/ijoso.2018.103.04. 